\title{
Use of photographs for measuring cupping in the optic disc
}

\author{
J. GLOSTER AND D. G. PARRY
}

Department of Experimental Ophthalmology, Institute of Ophthalmology, University of London

Our ability to diagnose chronic glaucoma and to control the disease still depends to a great extent on the observations that we can make on the intraocular pressure, the visual field, and the optic disc. In recent years the accuracy of tonometry has been improved and more efficient apparatus for testing visual fields has been produced, although it is common experience that the value of visual field testing may be limited by the subjective element in the procedure. It is now widely appreciated that solving the problem of accuracy of measurement of intraocular pressure does not solve all the problems of the diagnosis and management of glaucoma, because there is no simple relationship between the level of that pressure and the degree or the progression of visual damage. By contrast, it might be expected that the appearance of the optic disc should be closely related to the degree of visual damage and should be amenable to objective assessment. In practice, however, most of us find that although we can often confidently recognize an optic disc as glaucomatous or non-glaucomatous, there are also some discs which cause us great difficulty when we try to make this differentiation. Furthermore, there is sometimes a discrepancy between the amount of recognizable glaucomatous change in the disc and the degree of associated visual field change. These considerations, and others, suggest either that our present methods of observing the disc do not reveal the early features of glaucomatous damage, or that we are not yet aware of the earliest changes, or that, although we recognize certain features as pathological, we do not observe them with sufficient precision.

It is generally true that when recognition of glaucomatous damage to the disc can be made with the ophthalmoscope there is some loss of visual field; clearly, it would be far more satisfactory if we could recognize glaucomatous changes in the disc with certainty before visual loss occurred, and the need to do this is important if we believe that not all cases of ocular hypertension progress to glaucoma, and that such cases, although they must be kept under careful observation, need not necessarily be put on treatment.

Glaucomatous damage to the disc is manifested as extensive cupping and pallor, and therefore attempts to improve the position described above must be concerned with improving the methods of observing cupping and pallor, or with expressing these factors quantitatively. Generally speaking, more attention has been given to cupping than to pallor.

\section{(A) GUPPING OF THE DISG}

This has been assessed by the following techniques:

(i) Ophthalmoscopy

It is usually the extent of cupping that is observed. Direct observation may be supplemented by 
drawing the cupped disc or by using a measuring graticule (e.g. Pickard, 192 I ; Snydacker, 1964; Parr, 1966; Armaly, 1969, 1970). The depth of cupping can also be estimated by the amount of change in dioptres needed to alter the focus from the rim to the floor of the cup (e.g. Elliot, 1922).

(ii) Slit-lamp microscopy (e.g. Fishman, 1970; Goldman, 196r)

A Hruby or Goldmann fundus lens can be used, or a goniolens when inspecting the angle.

\section{(iii) Photography}

Photographs may be in black and white or in colour, or may be combined with the projection of a special grid on to the surface of the disc, or may involve stereophotography and stereophotogrammetry (e.g. Snydacker, I964; Hollows and McGuiness, I966; Halberg, I969; Crock, 1970; Holm and Krakau, 1970; Gloster, 1971).

\section{(B) GOLOUR OF THE OPTIG DISG}

The colour of the disc and the assessment of glaucomatous pallor have been studied by:

\section{(i) Ophthalmoscopy}

This permits direct visual estimation of pallor or a comparison with a series of colorimetric standards (e.g. Bock, 1950; Berkowitz and Balter, 1970).

(ii) Densitometry of colour photographs of the disc (Gloster, 1969; Davies, 1970).

(iii) Photoelectric reflectometry (Gloster, I969).

In addition, the vascularity of the optic disc has been estimated by enumeration of the small vessels crossing the edge of the disc (Kestenbaum, I946) or by fluorescein angiography (Oosterhuis and Gortzak-Moorstein, 1970).

Measurement of the colour of the optic disc raises a number of problems as the following examples show. A disc which is really pale may appear pink when viewed through a lens undergoing nuclear sclerosis. The use of photography is valid only if there is reasonably true reproduction of the colour of the disc. Some of the colour of the disc is due to the diffusion into the tissues of the optic nervehead of light which has passed through and been coloured by the peripapillary choroid, so that the very interpretation of colorimetry of the disc is questionable (Gloster, 1973).

The relationship between the area of pallor and the size of the cup in the optic disc has been examined (Schwartz, Reinstein, and Lieberman, r973), and Schwartz (1973) has recently suggested that the extent of cupping and the extent of pallor should be described separately since the one may not be wholly dependent on the other. Even so, with the ophthalmoscope, the area of relative pallor is usually taken into account when estimating the extent of cupping although attention is also given to other features such as deflection of vessels at the rim of the cup and parallactic movement of the rim relative to the floor of the cup. With ordinary photographs, in which there are no binocular or parallactic contributions to give an impression of depth, we have to judge the area of cupping from (a) the presence of an obvious edge to the cup; $(b)$ deflection of the vessels on the disc; and $(c)$ a difference in colour between the floor of the cup and the rim of healthy tissue around it. It often happens that $(a)$ and $(b)$ do not give much help, and therefore the area of cupping has to be judged mainly from the colour difference (Miller, 1972).

The technique described in this paper is concerned mainly with photographing cupping of the optic disc in such a way that an enhanced colour contrast is obtained between the floor of the cup and the tissue forming the rim of the cup. 
Three types of photograph were taken:

(1) 'Ordinary' photographs, which were colour photographs of the optic disc taken in the usual way. (2) '8o B' photographs, so called because a Kodak Wratten 8o B filter was used in the illuminating pathway of the fundus camera; otherwise the photographs of the optic disc were taken in the usual way.

(3) 'Cyan ring' photographs, so called because an Ilford Cyan filter with a ring cut out of it, as described later, was placed in the illuminating pathway of the camera. This method depends upon the optical properties of the tissues of the optic nervehead and of the surrounding tissues. The tissues of the optic disc vary in their ability to reflect light and to diffuse light within themselves; thus, light is much more strongly diffused in the rim of tissue around a cup than in the floor of the cup (Gloster, 1973), whereas the reflection of light is stronger from the floor of a cup than from the rim around it. The tissues surrounding the optic disc are penetrated to different depths by lights of different wavelengths; red or orange light can easily enter the choroid and be scattered therein, whereas green or blue light hardly penetrates at all into the choroid of the normally pigmented human eye (Gloster, 1967, I968). In the method of photography described below, a ring of white light is projected around the optic disc; the longer wavelengths penetrate into the choroid, are scattered laterally and illuminate indirectly the rim of the cup so that the rim appears reddish pink; at the same time the whole optic disc is illuminated with green light which is more strongly reflected by the floor than by the rim of the cup. The overall result is that in the photograph the rim of tissue surrounding the cup appears pink while the floor of the cup appears green.

As in various studies by other authors the cup: disc ratio was measured in glaucomatous patients and in non-glaucomatous subjects and a relationship was sought between the magnitude of the ratio and the presence or absence of a glaucomatous field defect. An attempt was made in this investigation to discover how reliably the cup: disc ratio could be measured from a photograph of the disc. Thus the same observer measured the cup: disc ratio on two separate occasions on the same type of photograph of the same disc; he also measured the ratio on an ordinary photograph and on a 'cyan ring' photograph of the same disc and, lastly, two different observers measured the same series of photographs. Also the cup: disc ratio was measured in different ways in order to discover which way gave the best correlation with the presence or absence of a glaucomatous field defect.

\section{Methods}

Fundus photographs were taken on patients attending the Institute of Ophthalmology, either because they were under investigation as suspected cases of glaucoma, or in established cases because the photograph was required to help in the management of the condition, or in non-glaucomatous patient, because a fundus photograph was needed for some other reason. It was usually necessary for a glaus coma patient to stop using miotic drops for a period of several days before the pupil was dilated and if it was considered necessary, the intraocular pressure was controlled for this period with acetazoleamide. The pupils were dilated with homatropine and cocaine drops and/or phenylephrine.

All photographs were taken on Kodak High Speed Ektachrome film, using the West German Zeiss fundus camera, fitted with the motorized Nikon F back via a $\times 2$ auxiliary objective. This auxiliary objective is essential if accurate measurements are to be made on the final transparency, since the resolution of Ektachrome does not allow a great degree of enlargement. The film received standard E 4 processing.

The three types of fundus photographs were taken as follows:

(i) 'Ordinary' photographs were taken in the usual way at Flash $\mathrm{I}$.

(ii) ' 80 B' photographs were taken at Flash 3 with a double layer of Kodak Wratten 8o B filter in 
the illuminating pathway of the fundus camera. This is a light-blue filter which progressively reduces transmission towards the red part of the spectrum.

(iii) 'Cyan ring' photographs were taken at Flash 3 with a special filter mounted in the illuminating pathway of the fundus camera as shown diagrammatically in Fig. I. The special filter consists essentially of a piece of a blue-green colour filter (Ilford Cyan filter No. 307, gelatine), out of which a narrow ring has been cut. The dimensions of the ring and the filter are shown in Fig. 2. The filter is held in the camera by means of the carrier shown in Fig. 3. This enables the filter to be moved along
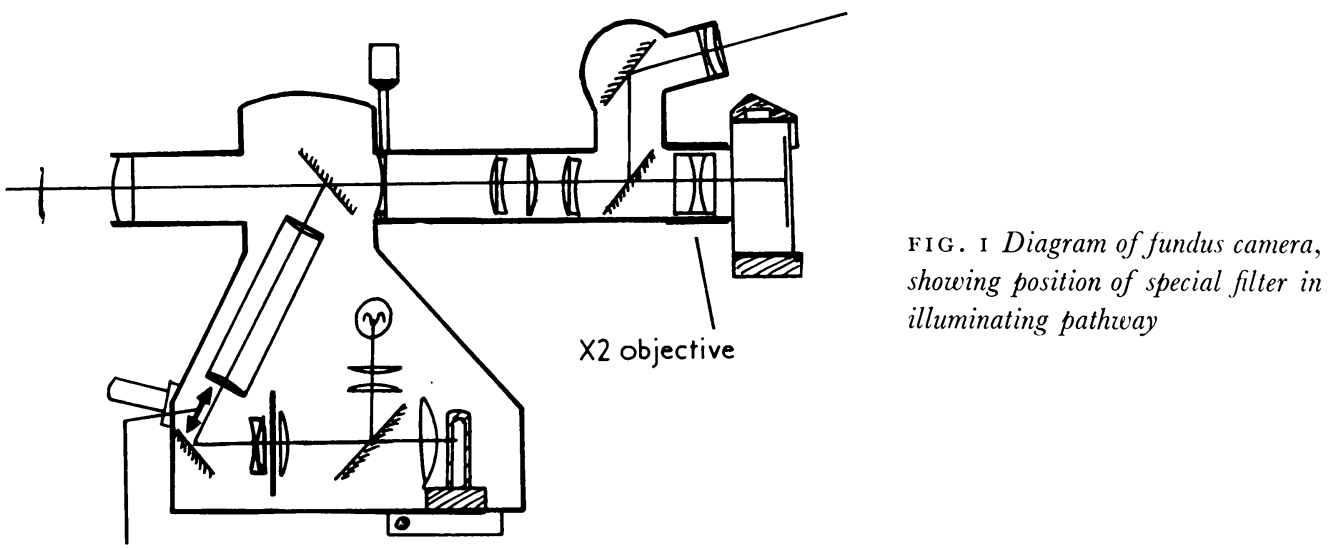

Plane of movement of cyan ring

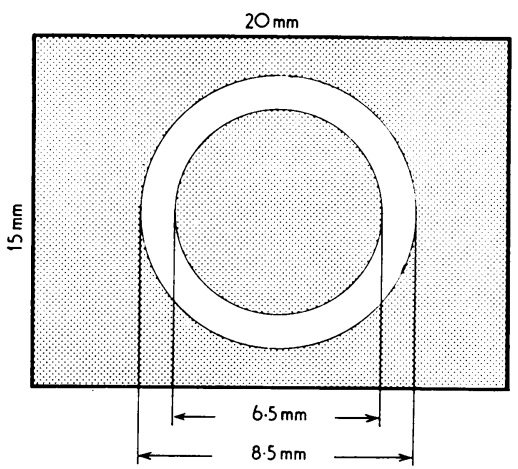

FIG. 2 Dimensions of cyan ring filter

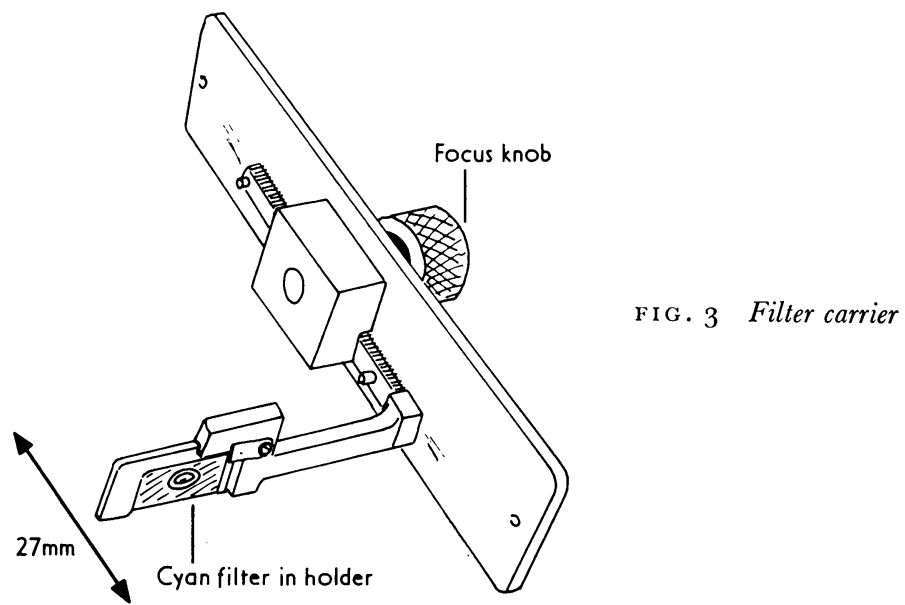


the optical axis in the illuminating pathway of the camera so that the ring can be focused on the fundus. The filter-carrier is fitted into the camera by replacing the original side of the camera with a copy which has a hole cut into it to accept the carrier (Fig. 4). The carrier can be inserted and removed as required. In order to take a 'cyan ring' photograph of the optic disc, adjustments are made so that the ring of white light from the special filter lies concentrically around the disc.

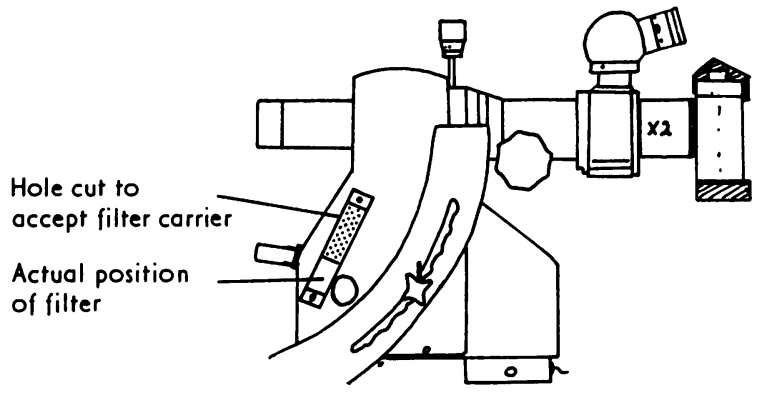

FIG. 4 Diagram of fundus camera,

Two focusing adjustments are needed:

(a) The ordinary adjustment to ensure that there is a sharp image of the disc on the film with particular reference to the astigmatic correction.

(b) An adjustment along the illuminating pathway of the position of the special filter so that a sharp image of the ring falls on the fundus around the disc.

Intraocular pressure was measured before and after dilatation. Finally, eserine drops were instilled, and the pupillary size and intra-ocular pressures were checked before the patient left the clinic. Visual fields were recorded on the Goldmann perimeter using the static method described by Gloster (1970) and by kinetic perimetry.

The following procedure was adopted for measuring the extent of cupping of the disc. The photograph was projected on to the back of a sheet of tracing paper, and one line was traced around the edge of the disc and another around the edge of the cup, care being taken with each photograph to preserve the correct orientation of the disc in the horizontal and vertical directions. The magnification was sufficient that, in the projected image, the diameter of the disc was between 10 and $20 \mathrm{~cm}$. Vertical lines were drawn through the temporal and nasal limits of the disc, and horizontal lines through the upper and lower limits forming a rectangle; the 'centre' of the disc was defined as the intersection of the diagonals of this rectangle. Vertical lines were also drawn through the temporal and nasal limits of the cup, and horizontal lines through the upper and lower limits. The narrowest part of the rim of the cup was marked on the tracing, and the diameter of the disc at this point was drawn so that it passed through the 'centre' of the disc, as defined above. The following measurements were then made:

(I) The vertical diameter of the cup divided by the vertical diameter of the disc $(\mathrm{Cv} / \mathrm{Dv})$.

(2) The horizontal diameter of the cup divided by the horizontal diameter of the disc ( $\mathrm{Ch} / \mathrm{Dh}$ ).

(3) The area of the cup divided by the area of the disc, as measured with the planimeter (Ac/Ad).

(4) The narrowest dimension of the rim divided by the diameter of the disc at that point $(r / d)$.

These geometrical constructions are shown in Fig. 5 (opposite).

\section{Results}

\section{(A) GENERAL APPEARANGE OF OPTIG DISG PHOTOGRAPHS}

The features of ordinary colour photographs of the optic disc are well known. In the $80 \mathrm{~B}$ photographs there was an exaggeration of the normal colour contrasts, especially that existing between the floor of the cup in an optic disc and the surrounding rim of healthy 


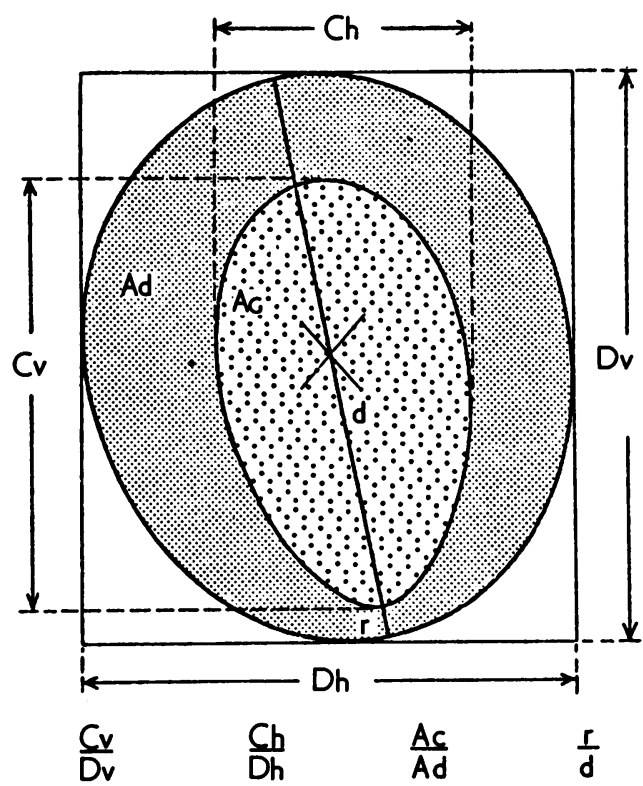

FIG. 5 Diagram showing measurements taken of cup and disc

tissue. The general effect was for pinks to appear less saturated and for reds to be more saturated; thus the floor of a cup often appeared to be almost white and the rim a dullish red.

An even greater exaggeration of colour contrast was obtained in the cyan ring photographs. Commonly, the floor of the cup in the disc appeared pale green and reflective and it was surrounded by a pink rim of healthy tissue. Around this in many photographs there was a narrow bright annulus with a greenish tinge. The surrounding fundus usually had a dull greenish tint sometimes broken up by a pink network made up of the larger choroidal vessels. The exaggeration of colour contrast may extend beyond the disc, for example, to areas of peripapillary choroidal atrophy. Some of these features can be seen in Figs 6 to 9 (overleaf).

Figs 6 and 7 show discs with physiological cups, and, Figs 8 and 9 pathological cups. In the latter it can be seen that, even though the remaining rim of tissue surrounding the cup becomes very narrow, it may nevertheless have a deep pink colour with this method of photography.

The general impression was that the position of the edge of the cup was more easily determined from the contrast between the green floor and the pink rim of the cyan ring photographs than from the contrast between the pale pink floor and the deeper pink rim of the cup in the ordinary photographs. It was quite obvious, however, that in some cyan ring photographs the transition from the green floor to the pink rim of the cup was not sharp enough to allow the edge of the cup to be defined by this colour change alone, and in such cases it was necessary to take into account deflections in the course of the blood vessels on the disc. Early lens changes sometimes reduced the contrast between the floor of the cup and the rim of the cup in ordinary photographs, but an improvement in this contrast was obtained with the cyan ring photograph, as can be seen in Figs Io and I I (overleaf), which show the same disc on the same occasion.

There was also better definition of the edge of the disc in the cyan ring photographs, although, in the normal disc, this usually applied only to small sectors of the edge. This improvement in definition of the edge of the disc was very obvious in one abnormal disc in which a pre-existing inflammatory process had made it impossible to see the position of 
the edge of the disc in an ordinary photograph, whereas there was no doubt as to its position in a cyan ring photograph.

In a series of Ioo discs photographed by the ordinary and cyan ring methods, the observer traced with a continuous line that part of the circumference of the cup or disc which he felt he could see with certainty, and with a dotted line that part which appeared doubtful. From these tracings it was found that on the average, the observer felt certain about the position of 57 per cent. of the circumference of the cup and 88 per cent. of the circumference of the disc in the orinary photographs, while the corresponding figures for the cyan ring photographs were 68 and 97 per cent.

As mentioned previously, there was frequently a narrow light band between the pink tissue of the disc and the peripapillary fundus, and this band was particularly distinct in the cyan ring photographs. In making the measurements, it was considered that the inner edge of the light band, adjoining the pink tissue of the disc, marked the edge of the disc rather than the outer edge of the light band which abutted the peripapillary fundus.

\section{(B) VARIABILITY OF MEASUREMENTS OF THE FOUR GUP: DISG RATIOS AND} THEIR INTER-OBSERVER VARIATIONS

37 discs were photographed in the ordinary way on colour film and also as cyan ring photographs, and using the 80 B filters, two satisfactory photographs being obtained by each of the three methods. These 222 photographs were then shuffled into a random sequence and tracings were made of them by one observer (J.G.) who dealt with thirty or forty in one session. The chances of two photographs of the same disc being traced consecutively was therefore low, and it was more likely that such photographs would be traced hours or even days apart. For each pair of photographs taken by the same method, the percentage difference between the two values for each ratio was calculated. The mean values of the ratios and the mean percentage difference between the ratios in paired photographs are given in Table I. It will be seen that the mean values for $\mathrm{Cv} / \mathrm{Dv}$ (the ratio of the vertical diameters of cup and disc), $\mathrm{Ch} / \mathrm{Dh}$ (the ratio of the horizontal diameters of cup and disc), and Ac/Ad (the ratio of the areas of cup and disc) were slightly greater in the cyan ring photographs than in the ordinary photographs, whereas the reverse was the case for $r / d$ (the ratio of the rim of the cup to the disc diameter). None of these differences was significant, but they suggest either that the size of the cup tends to be judged slightly larger, or that the size of the disc tends to be judged slightly smaller in the cyan ring photographs

Table I Mean values of the four cup: disc ratios and the repeatability of these values, measured by one observer in 37 discs, by different types of photography

\begin{tabular}{|c|c|c|c|c|c|c|c|c|c|}
\hline \multirow[b]{2}{*}{ Ratio } & & \multicolumn{2}{|c|}{$C v / D v$} & \multicolumn{2}{|c|}{$C h / D h$} & \multicolumn{2}{|c|}{$A c / A d$} & \multicolumn{2}{|r|}{$r / d$} \\
\hline & & $\begin{array}{l}\text { Mean } \\
\text { value }\end{array}$ & $\begin{array}{l}\text { Mean } \\
\text { percentage } \\
\text { difference }\end{array}$ & $\begin{array}{l}\text { Mean } \\
\text { value }\end{array}$ & $\begin{array}{l}\text { Mean } \\
\text { percentage } \\
\text { difference }\end{array}$ & $\begin{array}{l}\text { Mean } \\
\text { value }\end{array}$ & $\begin{array}{l}\text { Mean } \\
\text { percentage } \\
\text { difference }\end{array}$ & $\begin{array}{l}\text { Mean } \\
\text { value }\end{array}$ & $\begin{array}{l}\text { Mean } \\
\text { percentage } \\
\text { difference }\end{array}$ \\
\hline \multirow[t]{3}{*}{ Photography } & Ordinary & $0 \cdot 6 \mathrm{I}$ & $5 \cdot 8$ & $0 \cdot 63$ & $5 \cdot 3$ & $0 \cdot 38$ & $7 \cdot 3$ & o. I 44 & I I $\cdot 8$ \\
\hline & Cyan ring & $0 \cdot 62$ & $4 \cdot 8$ & $0 \cdot 65$ & $4 \cdot 0$ & $0 \cdot 4^{1}$ & $6 \cdot 1$ & $0 \cdot 136$ & $10 \cdot 7$ \\
\hline & 8 o B & $0 \cdot 60$ & $5 \cdot 3$ & 0.63 & 3.7 & $0.3^{8}$ & $6 \cdot 3$ & $0 \cdot 14^{2}$ & II $\cdot 0$ \\
\hline
\end{tabular}


(6)

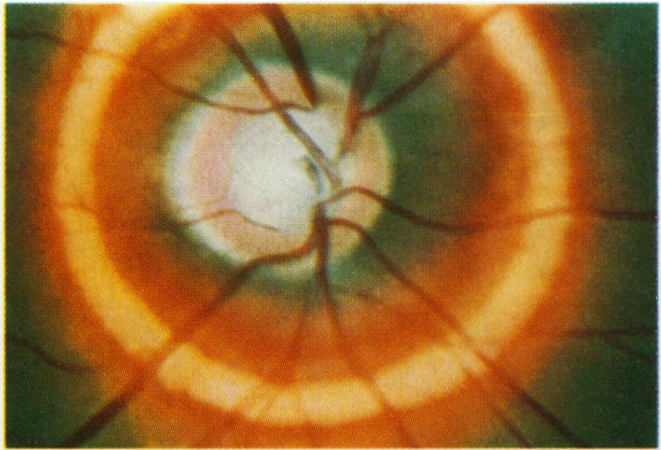

(8)

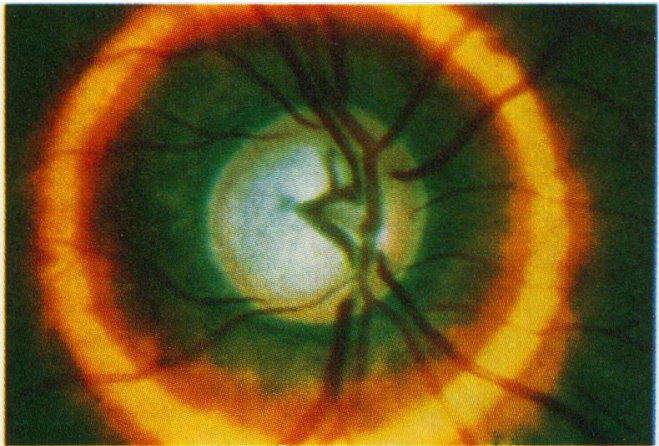

(IO)

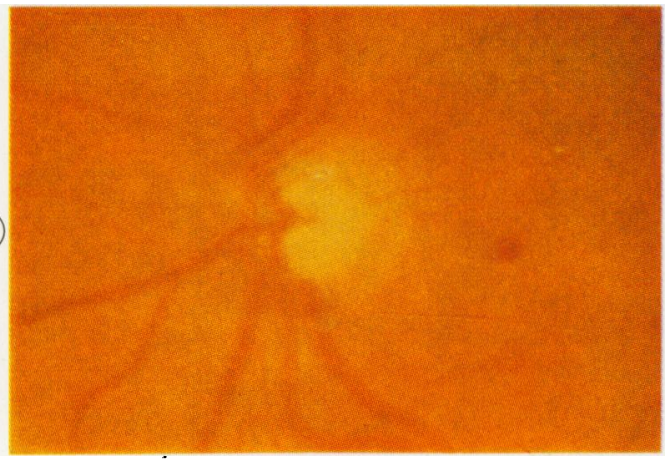

FIG. 6 Physiological cupping

FIG. 8 Pathological cupping

FI . Io Photograph of disc, taken without filter, in patient with early lens opacities

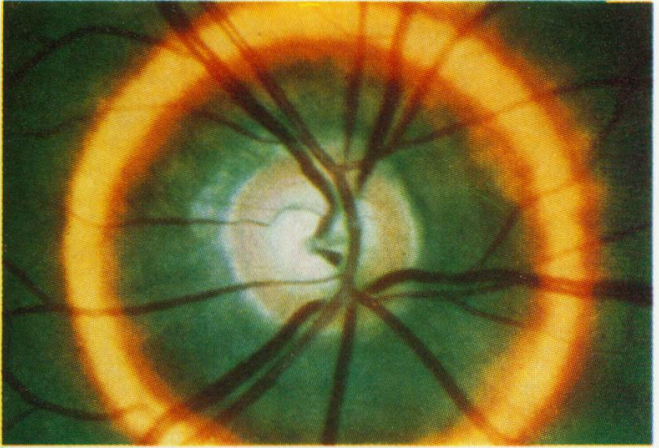

(7)

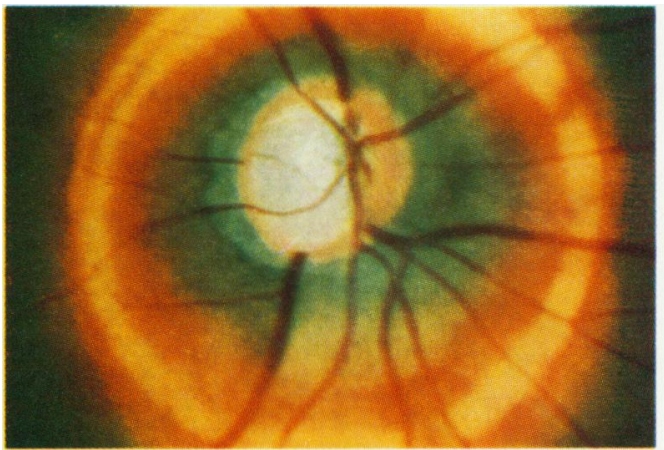

(9)

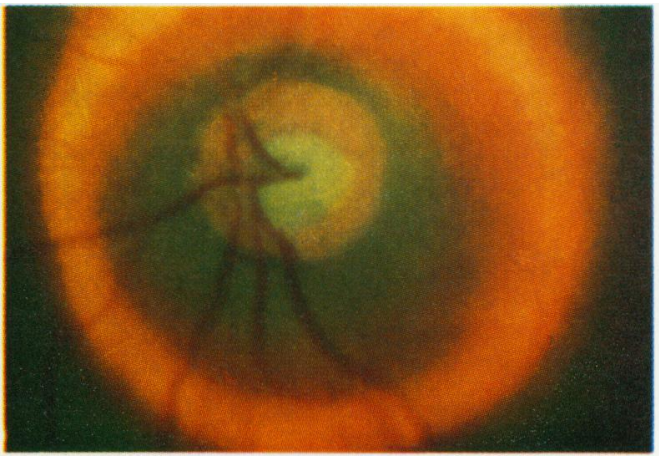

FIG. 7 Physiological cupping

FIG. 9 Pathological cupping

FIG. I I Same disc as Fig. 10, photographed with cyan ring filter 
as compared with the ordinary photographs. It appears that both these factors are involved because analysis of the planimetric results showed that, on the tracings, the average area of the cup was $64 \cdot \mathrm{I}$ sq. $\mathrm{cm}$. for the 74 cyan ring photographs (in Table I) and $6 \mathrm{I} \cdot 8 \mathrm{sq} . \mathrm{cm}$. for the corresponding ordinary photographs. The areas for the disc were 157.4 and 163.7 sq. cm. respectively.

The second point to be noted from Table I concerns the difference between measurements made by the same observer on a pair of photographs of the same disc. This was expressed for each pair as a percentage difference (i.e. the difference between the measurements divided by their mean and multiplied by roo). The mean percentage differences are given in Table I and it can be seen that these were lower for the cyan ring photographs than for the ordinary photographs; this finding was not statistically significant but it was consistent for all four ratios, suggesting a slightly better repeatability of measurements in cyan ring photographs as compared with ordinary photographs. There is a similar indication of slightly improved repeatability in the $80 \mathrm{~B}$ photographs.

Table II shows the range of inter-observer variations. Two observers (the authors of this papers) measured the four cup : disc ratios for 68 discs, one measurement being made from an ordinary photograph and the other from a cyan ring photograph. Care was taken to exclude the possibility of two photographs of the same disc being measured successively. The two observers differed considerably in their experience of examining glaucomatous optic discs. One observer (J.G.) had been looking at such discs for over 20 years in routine clinical work, while the other (D.G.P.) had been looking at them, mainly through a fundus camera, for 3 years only. Table II shows that there was a much greater variation between two measurements on the same disc when one measurement was made by one observer and another measurement by a second observer than when both measurements were made by the same observer on separate occasions ( $c f$.' Table I). Also the inter-observer variation was lower for the cyan ring photographs than for the ordinary photographs. This was most marked for Ac/Ad, the mean percentage differences for the ordinary and cyan ring photographs departing from each other by a statistically significant amount. It can be concluded, therefore, that compared with ordinary photographs, the cyan ring photographs possessed some features which reduced the inter-observer variation; this was presumably connected with the enhancement of colour contrast between the floor and rim of the disc and perhaps with the better definition of the edge of the disc.

Table II Inter-observer differences (per cent.) in the four cup: disc ratios. Two observers (7.G. and D.G.P.). 68 photographs of each type compared

\begin{tabular}{|c|c|c|c|c|c|}
\hline Ratio & & $C v / D v$ & $C h / D h$ & $A c / A d$ & $r / d$ \\
\hline \multirow[t]{2}{*}{ Photography } & Ordinary & II $\cdot 7$ & 13.8 & $22 \cdot 7$ & $28 \cdot 2$ \\
\hline & Cyan ring & $8 \cdot 9$ & $11 \cdot 5$ & $15 \cdot 0$ & $22 \cdot 3$ \\
\hline
\end{tabular}

(C) GORRELATION OF THE GUP : DisG RATIOS WITH THE PRESENGE OR ABSENGE OF a GLAUGOMATOUS FIELD DEFEGT

There were I Io eyes in which the optic discs had been photographed by the ordinary and by the cyan ring method and in which the visual fields had been tested on the Goldmann perimeter. This series included only eyes in which it could be said with certainty either that 
the fields were full or that there was a definite and characteristic glaucomatous field defect, the latter being defined according to the criteria suggested by Armaly (1969); that is to say $(a)$ an arcuate scotoma extending further than $45^{\circ}$ above or $5^{\circ}$ below the horizontal meridian, or $(b)$ a paracentral scotoma with a diameter greater than $5^{\circ}$, or $(c)$ a nasal step greater than $10^{\circ}$ in width.

Eyes in which these criteria of a defective field were not met or in which there was doubt about the field being full were not included in this series. Average values for the four cup : disc ratios are given in Table III, but these values merely reflect the well-known fact that advanced glaucomatous cups in eyes with a field defect tend to be larger than early glaucomatous cups or physiological cups in eyes which show no field defect. It is much more interesting to consider how well these ratios separate eyes which have field defects from those which do not, and whether one ratio achieves this separation better than another. In order to do this the I Io values of each ratio were listed in ascending magnitude for each type of photograph and the value was found which separated eyes with field defects from eyes with full fields, in such a way that the number incorrectly classified was at a minimum, and also ensuring that the proportion wrongly classified was the same for those with defects as for those with full fields.

Table III Mean values of the four cup:disc ratios in eyes showing glaucomatous field defects and in eyes with full fields

\begin{tabular}{|c|c|c|c|c|c|c|c|c|c|}
\hline \multirow{2}{*}{\multicolumn{2}{|c|}{$\frac{\text { Ratio }}{\text { Visual field }}$}} & \multicolumn{2}{|c|}{$C v / D v$} & \multicolumn{2}{|c|}{$C h / D h$} & \multicolumn{2}{|c|}{$A c / A d$} & \multicolumn{2}{|l|}{$r / d$} \\
\hline & & Full & Defective & Full & Defective & Full & Defective & Full & Defective \\
\hline \multirow[t]{2}{*}{ Photography } & Ordinary & $0 \cdot 53$ & $0 \cdot 77$ & 0.55 & $0 \cdot 72$ & $0 \cdot 30$ & $0 \cdot 56$ & $0 \cdot 182$ & 0.077 \\
\hline & Cyan ring & 0.54 & 0.77 & 0.57 & 0.74 & 0.31 & $0 \cdot 56$ & $0.17 \mathrm{I}$ & $0 \cdot 073$ \\
\hline
\end{tabular}

These results for the more experienced observer are given in Table IV and can be summarized as follows. If the vertical or horizontal diameter of the cup is more than twothirds of the corresponding diameter of the disc, one is likely to be dealing with an eye

Table IV Correlation between magnitude of cup:disc ratios and presence or absence of glaucomatous field defect in I I 0 discs (Observer 7.G.)

\begin{tabular}{|c|c|c|c|c|c|c|c|c|}
\hline \multirow{2}{*}{$\frac{\text { Ratio }}{\text { Type of photography }}$} & \multicolumn{2}{|l|}{$C v / D v$} & \multicolumn{2}{|l|}{$C h / D h$} & \multicolumn{2}{|l|}{$A c / A d$} & \multicolumn{2}{|l|}{$r / d$} \\
\hline & Ordinary & $\begin{array}{l}\text { Cyan } \\
\text { ring }\end{array}$ & Ordinary & $\begin{array}{l}\text { Cyan } \\
\text { ring }\end{array}$ & Ordinary & $\begin{array}{l}\text { Cyan } \\
\text { ring }\end{array}$ & Ordinary & $\begin{array}{l}\text { Cyan } \\
\text { ring }\end{array}$ \\
\hline $\begin{array}{l}\text { Value at which separation } \\
\text { into two classes is best }\end{array}$ & 0.68 & $0 \cdot 69$ & $0 \cdot 66$ & $0 \cdot 68$ & $0 \cdot 44$ & $0 \cdot 45$ & $0 \cdot 12$ & $0 \cdot 12$ \\
\hline $\begin{array}{l}\text { Percentage of measure- } \\
\text { ments giving correct } \\
\text { classification of discs as } \\
\text { regards presence or } \\
\text { absence of field defect }\end{array}$ & 89 & $9^{I}$ & $8 I$ & 82 & 87 & 85 & 90 & 90 \\
\hline
\end{tabular}


which has a glaucomatous field defect, and this is also the case if, in any place, the width of the rim of the cup is less than one-eighth of the diameter of the disc at that place. Separation of discs into their categories, as regards presence or absence of a field defect, was correct in about 90 per cent. of cases using the ratios $\mathrm{Cv} / \mathrm{Dv}$ or $\mathrm{r} / \mathrm{d}$, in about 86 per cent. of cases using Ac/Ad, and in only about 82 per cent. of cases using Ch/Dh. There was little difference between the results for the ordinary and cyan ring photographs. To give some idea of the range of values obtained, Fig. 12 shows the distribution of $\mathrm{Cv} / \mathrm{Dv}$ (cyan ring), which gave the best separation, and Fig. I 3 shows the distribution of $\mathrm{Ch} / \mathrm{Dh}$ (plain) which gave the poorest separation.
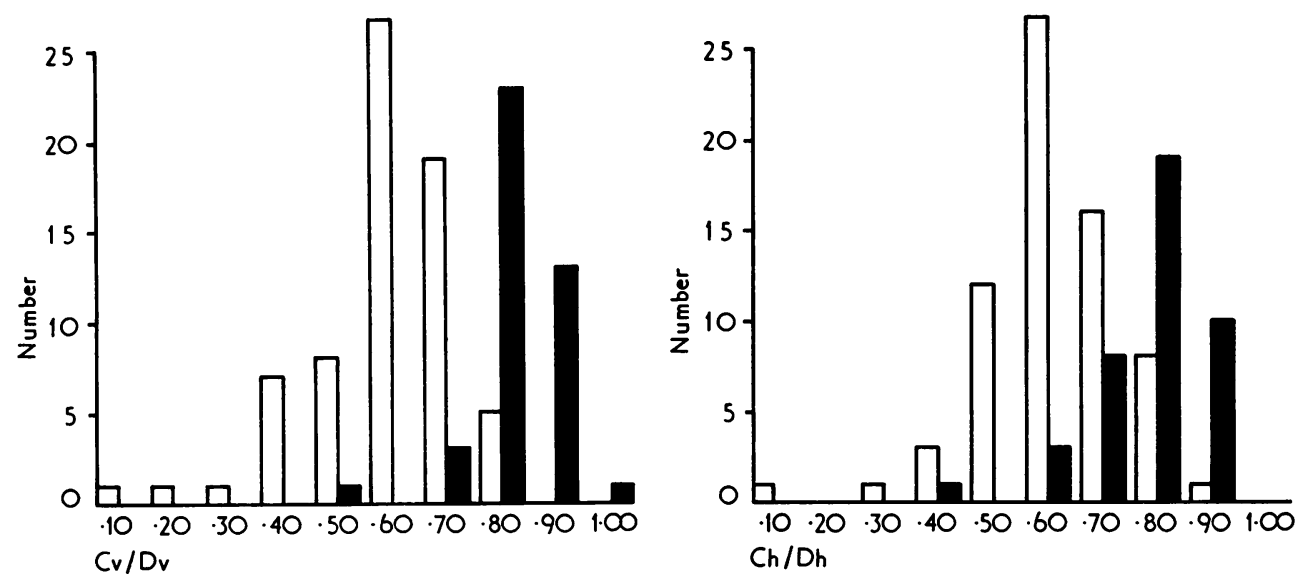

FIG. I 2 Frequency distribution of vertical : disc ratio, Cv/Dv

FI G. I 3 Frequency distribution of horizontal cup : disc ratio, Ch/Dh

Light columns: discs in eyes with no field defect

Dark columns: discs associated with glaucomatous field defects

A smaller series of $6_{5}$ discs was measured by the less experienced observer and his results appear in Table V. When these are compared with the first observer's results in Table IV two main points are obvious. While there was reasonably good agreement between the two observers on the values for $\mathrm{Cv} / \mathrm{Dv}$ and $\mathrm{r} / \mathrm{d}$ which gave the best separation of discs with regard to the presence or absence of a field defect, there was a much greater difference for $\mathrm{Ch} / \mathrm{Dh}$ and Ac/Ad. Secondly, the proportion of discs correctly classified was generally lower for the less experienced observer. Also, in Table V itself, it is clear that the less experienced observer achieved a better separation of discs into the two categories when he measured the cyan ring photographs than when the ordinary photographs were used.

\section{Discussion}

The enhancement of colour contrast between the floor of a cup and the rim of healthy disc tissue surrounding it, and between the disc edge and the surrounding fundus, was not only apparent in many of the cyan ring and $80 \mathrm{~B}$ photographs, but was also reflected in the results. Thus, greater proportions of the outlines of the cup and of the disc could be drawn with certainty in the cyan ring photographs than in the ordinary photographs. Also, the repeatability of measurement by one observer of the same type of photograph was greater for the cyan ring or $80 \mathrm{~B}$ photographs than for the ordinary ones (Table I), the agreement between the results of the two observers (J.G. and D.G.P.) was better with the cyan ring 
Table V Correlation between magnitude of cup: disc ratios and presence or absence of glaucomatous field defect in 65 discs (Observer D.G.P.)

\begin{tabular}{|c|c|c|c|c|c|c|c|c|}
\hline \multirow{2}{*}{$\frac{\text { Ratio }}{\text { Type of photography }}$} & \multicolumn{2}{|l|}{$C v / D v$} & \multicolumn{2}{|l|}{$C h / D h$} & \multicolumn{2}{|l|}{$A c \mid A d$} & \multicolumn{2}{|l|}{$r / d$} \\
\hline & Ordinary & $\begin{array}{l}\text { Cyan } \\
\text { ring }\end{array}$ & Ordinary & $\begin{array}{l}\text { Cyan } \\
\text { ring }\end{array}$ & Ordinary & $\begin{array}{l}\text { Cyan } \\
\text { ring }\end{array}$ & Ordinary & $\begin{array}{l}\text { Cyan } \\
\text { ring }\end{array}$ \\
\hline $\begin{array}{l}\text { Value at which separation } \\
\text { into two classes is best }\end{array}$ & $0 \cdot 66$ & $0 \cdot 65$ & 0.59 & $0 \cdot 59$ & $0 \cdot 37$ & 0.40 & $0 \cdot 14$ & $0 \cdot 14$ \\
\hline $\begin{array}{l}\text { Percentage of measure- } \\
\text { ments giving correct } \\
\text { classification of disc as } \\
\text { regards presence or } \\
\text { absence of field defect }\end{array}$ & 72 & 80 & 60 & 78 & 72 & 83 & 77 & 85 \\
\hline
\end{tabular}

than with the ordinary photographs (Table II), and the less experienced observer (D.G.P.) achieved a better separation of discs with regard to the presence or absence of a glaucomatous field defect when using the cyan ring photographs than when using the ordinary photographs (Table V). Although this enhancement of colour contrast was advantageous, it did not itself always ensure that the outline of the cup could be drawn with certainty and, as already mentioned, in some photographs it was necessary to make use of other clues, particularly deflection of the vessels as they passed over the edge of the cup. As is well known, there is usually no difficulty where the edge of a cup is steep; it is the gradually sloping edge which presents the problem, and in the cyan ring and $80 \mathrm{~B}$ photographs, although there was greater colour contrast, the transition was sometimes too gradual to permit a satisfactory definition of the edge of the cup. In this circumstance it also happens, of course, that other clues fail; for example, there may be no well-defined deflection of vessels at the edge of the cup.

It is obvious that a completely objective method of assessing the amount of cupping in an optic disc would be the most satisfactory, but even with a photograph in which the normal colour contrast has been exaggerated it is difficult to see how such an objective measurement could be made. Differential chromatic densitometry could perhaps form the basis of such a procedure but the presence of vessels on the disc is a complicating factor. The only procedure that yields a purely objective measurement of disc cupping is stereophotogrammetry (Crock, I970; ffytche, Elkington, and Dowman, 1973), and this is costly and time-consuming and takes no account of undermining: moreover, it is still in the experimental stages and it remains to be seen whether it can be developed into a routine procedure. Reflection colorimetry of the disc is feasible but there are problems concerning the meaning of this objective measurement (Gloster, 1970, 1973). For the time being it has to be accepted that subjective factors do enter into the assessment of the amount of cupping and there is evidence that they were involved in the results given in this paper. For example, the more experienced observer achieved a better separation of discs, as regards presence or absence of field defects, than did the less experienced observer ( $c f$. Tables IV and V). Presumably the more experienced the observer the better he can deduce the extent of cupping from looking at a photograph of the disc. In this connection it must be borne in mind that the patient was not examined at the same time and it is also doubtful if the 
ophthalmoscopic appearance of the disc could have been remembered in any detail at the time that the photograph was measured; also the present study is concerned with neither stereoscopic nor parallactic factors which can undoubtedly be utilized, although not necessarily in a quantitative way.

By measuring the disc photographs and calculating the ratios described, the more experienced observer was able to make a 90 per cent. correct separation of the discs into those associated with a field defect and those belonging to eyes with full fields (Table IV). In this connection it must be remembered that the discs were separated according to the presence or absence of a field defect and not according to whether they were thought to be glaucomatous, because this would have drawn in other clinical factors such as the intraocular pressure and so on. In any case the diagnosis of glaucoma is made in clinical practice partly on the appearance of the optic disc, and such an approach would have been completely inappropriate in the present study since the discs could not be characterized by reference to their own appearance if the intention was to see later how well they could be separated by means of measurements based on their appearance. It seemed best, therefore, to characterize them according to whether or not they were associated with a glaucomatous field defect.

It is interesting to note that, of the six discs in eyes with full fields which were "wrongly classified" on the basis of measurements of $\mathrm{Cv} / \mathrm{Dv}$ (i.e. would have been expected to show field defects), three were in patients in whom the fellow eye showed definite glaucomatous field defects, two in a patient with ocular hypertension (the one disc showing a small haemorrhage at its edge), and the last in another patient with ocular hypertension with a probable family history of glaucoma. It could therefore be argued that measurement had indicated that these discs were pathological, although our standard method of testing the visual fields had failed to do so.

Of the four different cup : disc ratios measured, it was found that $\mathrm{Cv} / \mathrm{Dv}$ and $\mathrm{r} / \mathrm{d}$ gave the best separation of discs according to the presence or absence of field defects (Tables IV and $\mathrm{V}$ ). The ratio giving the lowest separation was $\mathrm{Ch} / \mathrm{Dh}$; this was so for both observers and there was the possibility that this ratio was of less value because it could not be measured as reliably as $\mathrm{Cv} / \mathrm{Dv}$. This is because the upper and lower borders of cups (whether physiological or pathological) are often well defined, whereas the nasal and temporal borders are less easy to define. In a photograph, the exact position of the nasal border of a cup may be difficult to define because of the presence of fairly large vessels, and the temporal border may slope very gradually so that it is difficult to decide where the cup ends. It was found, however, that the observer (J.G.) measured $\mathrm{Ch} / \mathrm{Dh}$ slightly more reliably than $\mathrm{Cv} / \mathrm{Dv}$ in all three types of photograph (Table I) and therefore the explanation given above for the lower rate of separation with $\mathrm{Ch} / \mathrm{Dh}$ has to be rejected. The lower rate achieved with the ratio of the areas (Ac/Ad) is not surprising as this takes into account the horizontal diameters of the cup and disc as well as the vertical diameters.

It would appear, therefore, that the higher significance of $\mathrm{Cv} / \mathrm{Dv}$ as compared with $\mathrm{Ch} / \mathrm{Dh}$ means that the former ratio is related more closely to the basic pathological change from which arises the glaucomatous field defect. In this respect our findings support the view of Kirsch and Anderson (1973) that the development of a vertically oval shape by a cup in the disc constitutes the earliest detectable glaucomatous change.

\section{Summary}

(I) Four cup : disc ratios were measured from photographs of optic discs: 
(a) $\mathrm{Cv} / \mathrm{Dv}$, the ratio of the vertical diameters of the cup and disc respectively;

(b) $\mathrm{Ch} / \mathrm{Dh}$, the corresponding ratio for the horizontal diameters;

(c) Ac/Ad, the area of the cup divided by the area of the disc;

(d) $\mathrm{r} / \mathrm{d}$, the narrowest part of the rim round the cup divided by the diameter of the disc.

(2) A special method of photography is described for enhancing the colour contrast between the floor of the cup in an optic disc and the surrounding rim of healthy tissue; this results in an improvement in the reliability of measurement of the above ratios.

(3) The ratios were examined for their ability to separate discs in eyes with full fields from those in eyes with glaucomatous field defects. Up to go per cent. of discs could be separated in this way, the best separation being achieved with the vertical diameter ratio, Cv/Dv.

\section{References}

ARmaly, м. F. (I969) Trans. Amer. Acad. Ophthal. Otolaryng., 73, 898 - (1970) Invest. Ophthal., 9, 425

Berkowitz, J. s., and balter, s. (1970) Amer. 7. Ophthal., 69, 385

BOCK, R. H. (1950) Ophthalmologica (Basel), 120, I 74

GROCK, G. L. (1970) Trans. ophthal. Soc. U.K., 90, 577

DAVIES, E. W. G. (1970) Exp. Eye Res., 9, 106

ELliot, R. H. (I922) "A Treatise on Glaucoma", 2nd ed., p. 201. Frowde and Hodder and Stoughton, London

Ffytche, T. J., Elkington, A. R., and Dowman, I. J. (I973) Trans. ophthal. Soc. U.K., 93, 25I

Fishman, R. S. (1970) Arch. Ophthal. (Chicago), 84, 590

GLOSTER, J. (1967) Exp. Eye Res., 6, 187

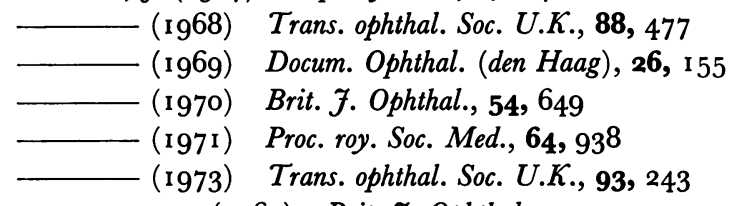

goldmann, H. (Ig6r) Brit. 7. Ophthal., 45, 449

halberg, G. P. (1969) Arch. Ophthal. (Chicago), 82, I 49

hollows, F. C., and mcguiness, R. (ig66) Trans. ophthal. Soc. Aust., 25, 33

holm, O. L., and Krakau, c. E. T. (1970) Ann. Ophthal., I, 327

KESTENBAum, A. (1946) "Clinical Methods of Neuro-ophthalmologic Examination", p. 81. Grune and Stratton, New York

KIRSGH, R. E., and ANDerson, D. R. (1973) Amer. 7. Ophthal., 75, 442

MILleR, s. J. H. (1972) Trans. ophthal. Soc. U.K., 92, 563

OOSTERHUIS, J. A., and GORTZAK-MOORSTEIN, N. (1970) Ophthalmologica (Basel), r6o, 33 I

PARR, J. C. (1966) Trans. ophthal. Soc. N.Z., I8, 93

PICKARD, R. (I92 I) Proc. roy. Soc. Med., I4, Sect. ophthal., 3 I

schWARTz, B. (1973) Arch. Ophthal. (Chicago), 89, 272

- REINSTEIN, N. M., and LIEBERMAN, D. M. (I973) Ibid., 89, 278

SNYDACKer, D. (I964) Amer. F. Ophthal., 58, $95^{8}$ 